\title{
Machado de Assis inédito e atual
}

Hélio Seixas Guimarães ${ }^{I}$

O M PEQUENO volume recém-lançado, com a discrição que caracteriza as publicações da Academia Brasileira de Letras, oferece ao leitor cinco textos de Machado de Assis inéditos em livro. Eles jaziam até agora esquecidos nas páginas dos periódicos oitocentistas onde foram publicados pela primeira e única vez: uma crônica, um editorial, um conto inacabado, uma conferência e um prólogo à tradução de um poema.

Os textos, veiculados em periódicos variados entre junho de 1859 e fevereiro de 1875 , cobrem um período decisivo da formação do escritor, desde praticamente sua estreia literária, em 1859, com o soneto “À Ilma. Sra. D. P. J. A.”, até meados da década de 1870, quando o escritor se apossava dos instrumentos que lhe permitiram produzir os romances e contos que lhe garantiriam a posteridade.

O primeiro fato notável nessa verdadeira raspa de tacho da produção machadiana é a presença de textos de vários gêneros, indicativos da versatilidade que marcou toda a produção do escritor. Embora ao longo do século XX tenha sido consagrado pela prosa ficcional, Machado jamais renegou os escritos da juventude nem qualquer dos gêneros que praticou. E ao longo da vida inteira praticou todos, incluindo poesia, teatro, crítica, crônica, contos, romances.

Outro fato notável é a atualidade de alguns desses textos, alguns deles escritos há mais de 150 anos. É o caso da crônica que abre o volume, originalmente publicada em O Paraíba de 26 de junho de 1859. Nela, o cronista de vinte anos recém-completados trata da mudança recente no Ministério da Fazenda e da iminência da publicação, pelo novo ministro, de medidas econômicas controversas. Elas representariam um golpe sobre o crédito e lançariam a população em mais uma das inúmeras crises de que é feita a história do país.

O jovem cronista ri-se das pretensões do ministro atual e enaltece o seu antecessor: "A praça tem ainda em lembrança o ministro que lhe preveniu uma crise, quando toda a Europa sofria. Do atual ministro da Fazenda há de lhe ficar as recordações que deixam os temporais e os terremotos" (p.19)

Diante das rusgas e diferenças entre o antigo e o atual, comenta:

O projeto bancário do sr. Ministro da Fazenda não pode merecer o apoio da gente sensata. É a varinha de condão com que S. Excia. pretende criar um novo Pactolo, é um novo parto da fábula: $S$. Excia. fez de montanha, e deu à luz o seu ratinho econômico, que não era de alfândega, e que por conseguinte veio ético e mirrado. Deus salve o monstrengo que começa a ser menino Jesus da maioria, e daqueles que folgarão em dançar sobre as ruínas da pátria. (p.19)

Machado não economiza nas alegorias, mas também não se deixa enganar, nem escamoteia a pergunta crucial: "É o eterno destino do povo rolar como Sísifo antigo a pedra das suas liberdades e vê-la despenhar-se de contínuo?” (p.18). 
Os comentários chamam a atenção para a visão aguda sobre os ciclos econômicos - com todas as suas consequências políticas e sociais -, que há séculos dão as cartas no país, independentemente dos nomes da ocasião, que, seja no século XIX, seja no século XXI, fazem a máquina enguiçada mover-se em espasmos.

No editorial escrito para o Diário do Rio de Janeiro em dezembro de 1866, Machado toca noutra instituição fundamental para o emperramento da vida no país: o espírito de porco que parece reger a política nacional. $\mathrm{O}$ editorial trata da visita de Saldanha Marinho, então presidente da província de Minas Gerais, a um coronel de Piranga, na região de Ouro Preto, com o intuito de buscar apoio da população local à Guerra do Paraguai, então em curso.

$\mathrm{O}$ editorialista anônimo conta que o entusiasmo da população com a visita do presidente é rapidamente minado pelo Partido Conservador, que em seus discursos associa a campanha no Paraguai a uma campanha do Partido Liberal. Eis o comentário de Machado: "Não se convencem de que isto é uma nação, e não uma grande aldeia, exposta ora ao mexerico do soalheiro, ora ao distúrbio da praça pública". E conclui lançando uma pergunta, que deixa no ar: "Mas são os adversários que sofrem com essa guerra mesquinha, ou é a província toda, o país inteiro?" (p.21).

Do gênero conto, o organizador garimpou um texto publicado na revista O Futuro, para a qual Machado colaborou no início da década de 1860. Trata-se de "Um parêntesis na vida", conto incompleto que ensaia a representação dos estados de consciência alterada que atingirão sua perfeição no delírio de Brás Cubas, no enlouquecimento de Quin- cas Borba, nas crises de ciúme de Bento Santiago. No caso do conto, uma febre começa a acometer o protagonista exatamente no momento em que a história fica interrompida.

É nessa seção que se nota com mais nitidez a dedicação do incansável pesquisador Mauro Rosso na organização do volume. Não se trata apenas da reunião do material inédito em livro. O organizador recompõe a história da publicação de cada texto, situando-o no contexto mais amplo da produção machadiana.

Assim, Rosso indica como o conto é referenciado por Machado em duas de suas crônicas publicadas no mesmo $O$ Futuro, e mostra ainda como esse conto, deixado incompleto em 1863, serviu de base para a composição de outro, "Felicidade pelo casamento", publicado em 1866 no Jornal das Famílias. Para demonstrar o reaproveitamento, coteja e publica lado a lado vários trechos idênticos dos dois contos, explicitando também a prática machadiana de reescritura de suas histórias curtas, às vezes publicadas com modificações significativas entre uma versão e outra, às vezes com títulos diferentes, ou sob assinaturas diferentes.

O texto mais longo do volume é uma tradução feita por Machado de Assis para a Instrução Pública, publicada aos pedaços entre 1873 e 1874. Trata-se da tradução, do francês, da série de conferências intituladas "Higiene para uso dos mestres-escolas (pelo dr. Gallard)", um pequeno guia prático para uso dos preceitos de higiene e dos primeiros socorros então recém-formulados pela medicina moderna - hoje assimilados e tornados lugares-comuns.

Machado, sempre tão irreverente com a medicina e o higienismo, parece ter aproveitado desse texto menos o 


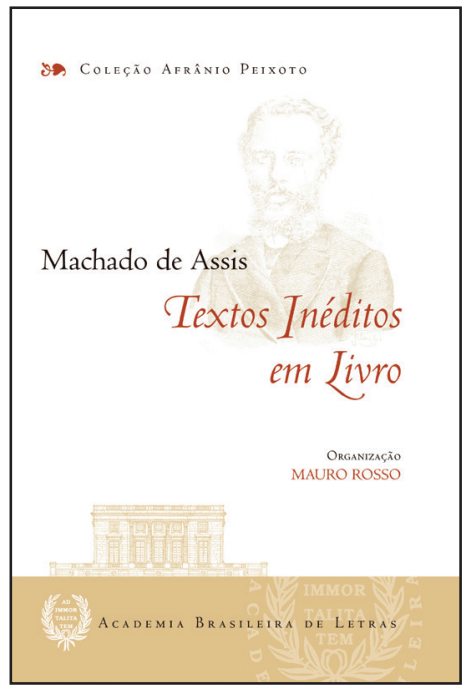

ASSIS, M. de. Machado de Assis-textos inéditos em livro. Org. Mauro Rosso.

Rio de Janeiro: Academia Brasileira de Letras, 2014. 172p.

conteúdo, completamente alinhado à doutrina higienista, e muito mais o tom e a forma com os quais situações aflitivas são tratadas com isenção, frieza e muito pragmatismo pelo dr. Gallard e seu tradutor. Eis a descrição de uma hemorragia de artéria:

Facilmente compreendereis que se conseguirdes segurar a ponta da artéria, enrolar-lhe um fio e dar um nó sólido, fechareis desse modo a abertura por onde sai o sangue. Os cirurgiões fazem mui habilmente essa operação separando a ponta da artéria com uma pinça, que lhes permite trazer para fora da ferida a ponta da artéria, a fim de a ligar mais facilmente; nem sempre há disposição, e como em tal caso o perigo consiste antes em não fazer nada do que em fazer mal, é mister não hesitar em segurar com os dedos as carnes ensanguentadas, apertando de modo que pare o sangue, o que prova que a artéria está segura, depois, passa-se em volta da massa de carne assim segura um laço que se aperta fortemente. (p.112)

Qualquer relação com o modo distanciado e frio com o qual muitos dos narradores machadianos tratam de situações extremas e aflitivas (lembremos de "A causa secreta", "Pai contra mãe", “O autor de si mesmo"...) talvez não seja mera coincidência.

Finalmente, o volume contém um Prólogo à bela e famosa tradução do canto XXV do Inferno, de Dante, no qual diz como e por que se dedicou a traduzir "um dos melhores quadros saídos da imaginação daquele homem extraordinário que Florença deu ao mundo" (p.14l). Publicado n'A Instrução Pública em fevereiro de 1875, o prólogo foi posteriormente abandonado nas novas publicações do poema em livro, a começar da sua publicação com o título "Dante (Inferno, canto XXV)", em Ocidentais.

(Curiosamente, não está mencionada nesse volume a publicação anterior do poema, que segundo indicação de Galante de Sousa teria saído em 25 de dezembro de 1874 nas páginas de $O$ Globo. Infelizmente, a coleção desse jornal disponível na Hemeroteca Digital da Biblioteca Nacional está desfalcada de alguns números, entre eles o dessa data, de modo que não foi possível conferir se houve mesmo a publicação indicada por Galante.)

O princípio que regeu a cuidadosa organização de Mauro Rosso, um reconhecido apaixonado pela obra de Machado de Assis, foi o de que esses e quaisquer outros textos de Machado, por mais fragmentários e circunstanciais que sejam, ajudam a compreender me- 
lhor os processos de criação do escritor, cuja obra precisa ainda ser lida "como um todo coerentemente organizado", conforme a boa e necessária proposta de Silviano Santiago.

Para demonstrar a coerência desse todo, cada um dos inéditos vem acompanhado de um comentário e/ou de um estudo assinado pelo organizador, mesmo correndo-se o risco de sobrecarregar o conjunto, subordinando o que mais interessa - os textos de Machado, vários deles muito breves - às explicações que cercam esses textos.

Entretanto, a iniciativa da edição, oportuna e louvável, merece todos os elogios. Junto com a monumental correspondência, que desde 2008 vem sendo publicada pela ABL, com coordenação de Sergio Paulo Rouanet e notas de Irene Moutinho e Sílvia Eleutério, os inéditos resgatados são mais uma contribuição importante para a composição da figura e da obra prismáticas de Machado de Assis.

Hélio Seixas Guimarães é professor livredocente na Universidade de São Paulo e pesquisador do CNPq. @ - hsg@usp.br

I Faculdade de Filosofia, Letras e Ciências Humanas, Universidade de São Paulo, São Paulo/SP, Brasil. 